\title{
Cell-Free Protein Synthesis Using S30 Extracts from Escherichia coli RFzero Strains for Efficient Incorporation of Non-Natural Amino Acids into Proteins
}

\author{
Jiro Adachi ${ }^{1,4, \dagger}{ }^{\dagger}$ Kazushige Katsura ${ }^{1,2,5, \dagger}$, Eiko Seki ${ }^{1,3,6,+}$, Chie Takemoto ${ }^{1,2,5}$, \\ Mikako Shirouzu 1,2,5, Takaho Terada ${ }^{1,3,6}$, Takahito Mukai ${ }^{1,2,7}$, Kensaku Sakamoto ${ }^{1,2,8}$ (D) and \\ Shigeyuki Yokoyama 1,3,6,*(D) \\ 1 RIKEN Systems and Structural Biology Center, Yokohama 230-0045, Japan; jiro.adachi@riken.jp (J.A.); \\ kazushige.katsura@riken.jp (K.K.); eiko.seki@riken.jp (E.S.); chie.takemoto@riken.jp (C.T.); \\ mikako.shirouzu@riken.jp (M.S.); tera@riken.jp (T.T.); takahito.mukai@rikkyo.ac.jp (T.M.); \\ kensaku.sakamoto@riken.jp (K.S.) \\ 2 Division of Structural and Synthetic Biology, RIKEN Center for Life Science Technologies, \\ Yokohama 230-0045, Japan \\ 3 RIKEN Structural Biology Laboratory, Yokohama 230-0045, Japan \\ 4 Laboratory for Cell-Free Protein Synthesis, RIKEN Center for Biosystems Dynamics Research, \\ Osaka 565-0874, Japan \\ 5 Laboratory for Protein Functional and Structural Biology, RIKEN Center for Biosystems Dynamics Research, \\ Yokohama 230-0045, Japan \\ 6 RIKEN Cluster for Science, Technology and Innovation Hub, Yokohama 230-0045, Japan \\ 7 Department of Life Science, College of Science, Rikkyo University, Tokyo 171-8501, Japan \\ 8 Laboratory for Nonnatural Amino Acid Technology, RIKEN Center for Biosystems Dynamics Research, \\ Yokohama 230-0045, Japan \\ * Correspondence: yokoyama@riken.jp; Tel.: +81-45-503-9196 \\ + These authors equally contributed to this study.
}

Received: 19 December 2018; Accepted: 21 January 2019; Published: 24 January 2019 updates

\begin{abstract}
Cell-free protein synthesis is useful for synthesizing difficult targets. The site-specific incorporation of non-natural amino acids into proteins is a powerful protein engineering method. In this study, we optimized the protocol for cell extract preparation from the Escherichia coli strain RFzero-iy, which is engineered to lack release factor 1 (RF-1). The BL21(DE3)-based RFzero-iy strain exhibited quite high cell-free protein productivity, and thus we established the protocols for its cell culture and extract preparation. In the presence of 3-iodo-L-tyrosine (IY), cell-free protein synthesis using the RFzero-iy-based S30 extract translated the UAG codon to IY at various sites with a high translation efficiency of $>90 \%$. In the absence of IY, the RFzero-iy-based cell-free system did not translate UAG to any amino acid, leaving UAG unassigned. Actually, UAG was readily reassigned to various non-natural amino acids, by supplementing them with their specific aminoacyl-tRNA synthetase variants (and their specific tRNAs) into the system. The high incorporation rate of our RFzero-iy-based cell-free system enables the incorporation of a variety of non-natural amino acids into multiple sites of proteins. The present strategy to create the RFzero strain is rapid, and thus promising for RF-1 deletions of various E. coli strains genomically engineered for specific requirements.
\end{abstract}

Keywords: cell-free protein synthesis; non-natural amino acid; release factor 1; RF-1; 3-iodo-L-tyrosine; RFzero-iy 


\section{Introduction}

Cell-free protein synthesis has become the preferred method for protein preparations, as it offers numerous advantages over bacterial and eukaryotic cell-based expression method [1]. The open nature of an in vitro system facilitates modifications and optimizations of reactions, and it enables the synthesis of difficult proteins, such as physiologically toxic proteins, integral membrane proteins, and large protein complexes, by allowing supplementation with multiple additives, such as chemicals, detergents, lipids, and molecular chaperones. For example, large amounts of membrane proteins are successfully generated by cell-free systems with detergents and lipids as additives [2]. Precise stable isotope labeling of proteins, which are inevitably metabolized upon in vivo expression, could be achieved by using specific inhibitors of intracellular metabolic reactions [3].

The Escherichia coli cell extract-based cell-free protein synthesis is one of the most practical and efficient cell-free systems, and thousands of proteins have been synthesized for functional and structural studies [1], and for pharmaceutical development. Methods for engineering the E. coli genomic DNA are now well established, and thus the development of novel cell extracts for cell-free protein synthesis has become possible [4,5].

The site-specific incorporation of non-natural amino acids into proteins has become an important technology for protein engineering. More than 100 non-natural amino acids have been site-specifically incorporated into proteins for various purposes, such as conjugations with fluorescent probes, polymers, and drugs [6]. Some amino acids generated by protein post-translational modifications can be translationally incorporated into proteins to make them directly in the modified states [7]. Aminoacyl-tRNA synthetase (aaRS) and tRNA pairs from bacteria and archaea, which are orthogonal to or not recognized by the endogenous aaRS and tRNA pairs are used. However, non-natural amino acids are sometimes toxic or poor in cellular uptake and are fundamentally difficult to incorporate into proteins by in vivo protein expression methods. The excess amounts of the orthogonal tRNA and aaRS pair for non-natural amino acid incorporation also exhibit cellular toxicity during in vivo expression. Therefore, cell-free protein synthesis is a suitable technology for site-specific incorporations of non-natural amino acids, not only for its ability to synthesize difficult proteins as mentioned above, but also for its non-cellular nature [8,9].

The amber (UAG) stop codon is commonly reassigned as a target codon to incorporate a non-natural amino acid during translation, while it is normally recognized as a translation termination signal by release factor 1 (RF-1) in E. coli. To improve the incorporation efficiency of a cell-free system using the UAG codon, various strategies to minimize the RF-1 activity in the cell extract have been attempted, such as by adding RF-1-inactivating RNA aptamer to the reaction mixture [10], reconstituting the cell-free system without RF-1 [11], and engineering the RF-1 for tag-mediated removal from the extract [12]. However, despite these manipulations, low levels of RF-1 activities often remain within these cell extracts.

Several RF-1-free E. coli strains have been developed by deleting the RF-1-encoding gene prfA from the genomic DNA [13-16], giving rise to another strategy, to use the cell extracts of such RF-1-free E. coli strains for protein synthesis. The E. coli genome originally harbors over 300 genes ending with UAG stop codons, and thus the simple deletion of $\operatorname{prfA}$ or the disabling of the RF-1 function severely affected the growth of E. coli, resulting in low protein productivity. In contrast, the replacement of a large number of UAG codons with other stop codons allowed the deletion of the essential prfA gene, with minimal effects on the growth and protein production. Using the cell extracts from these strains, several cell-free protein synthesis methods exhibited high incorporation efficiencies [17-19]. B-60. $\Delta$ A::Z and B-95. $\Delta$ A are RF-1-free E. coli strains, with genomes in which 60 and 95 UAG codons were mutated, respectively [16]. Using cell extracts from these strains, we have reported cell-free protein synthesis with multiple site-specific incorporations of non-natural amino acids [20].

Meanwhile, many E. coli strains have been generated specifically for various purposes, by deleting multiple enzymes or metabolic pathways. Some of these strains have been designed to incorporate non-natural amino acids. As an example, for $\mathrm{O}$-phosphotyrosine incorporation, five genes for endogenous 
phosphatases were deleted from the E. coli genome [21]. To utilize the functions of these diverse E. coli strains, the methods to create their RF-free versions, by replacing a large number of UAG codons, require extensive gene editing and laborious work. Similarly, the additions of specific properties to these UAG codon-replaced RF-free E. coli strains also require multiple genome editing steps.

Therefore, we have generated a rapid method to create a new RF-1-free E. coli strain, RFzero, with only a minimal decrease of the E. coli growth rate [22]. This strategy, involving the transformation of a BAC plasmid harboring seven coding sequences for deleting $\operatorname{prf} A$, is quite rapid and simple, as compared to the above strategies with numerous genomic engineering steps. Only one mutation of a gene is required to create RF-1-free E. coli strains from diverse E. coli strains. In practice, we have generated RFzero strains from different $E$. coli strains, including the E. coli K-12 strains BW25113, W3110, and HMS174(DE3) and the E. coli B strain BL21(DE3), for various purposes [23,24]. The RFzero-iy strain was generated for incorporating 3-iodo-L-tyrosine (IY) [25], with the expression of a previously developed Methanococcus jannaschii tRNA ${ }^{\mathrm{Tyr}}$ variant and a tyrosyl-tRNA synthetase variant, iodoTyrRS. When this RFzero-iy strain was cultured with IY, over 300 gene transcripts of the E. coli genome that end with UAG stop codons were translated to IY, and thus, the protein products have several additional residues at the C-termini. These translations prevent ribosomes from stalling at the UAG sites, which should have arisen from the deletion of RF-1. Thus, the RFzero-iy strain recovered vigorous growth when it was cultured with IY [25]. Using the RFzero-iy strain, other non-natural amino acids could be incorporated into proteins, by supplementing the media with specific non-natural amino acids during the culture, although these non-natural amino acids showed decreased protein productivities [23]. Our preliminary trial using the cell extract from the RFzero BL21(DE3) strain incorporated four acetyllysines into histone $\mathrm{H} 4$, with high efficiency [23].

In this study, we present the precise strategy for the site-specific incorporation of various non-natural amino acids using this RFzero extract-based cell-free system. The cell extracts were created from the RFzero-iy strains. We describe the detailed method for the cell extract preparation to overcome the distinctive difficulties of using the RFzero strain, and demonstrate the creation of two RFzero-iy strains from different $E$. coli strains. We confirmed the incorporations of non-natural amino acids (Figure 1A) with high efficiency and excellent productivity by cell-free protein synthesis, using a single type of cell extract (Figure 1B). The incorporation was not restricted to the use of TyrRS variants, but it was applicable to tRNA ${ }^{\mathrm{Pyl}} /$ PylRS variants pairs, simply by their supplementation into the reaction solution. Together with the rapidity of constructing new RF-1-free strains from E. coli strains specifically generated for various purposes, our cell-free protein synthesis strategy will expand the adaptation of these diverse E. coli strains to incorporate non-natural amino acids into proteins.

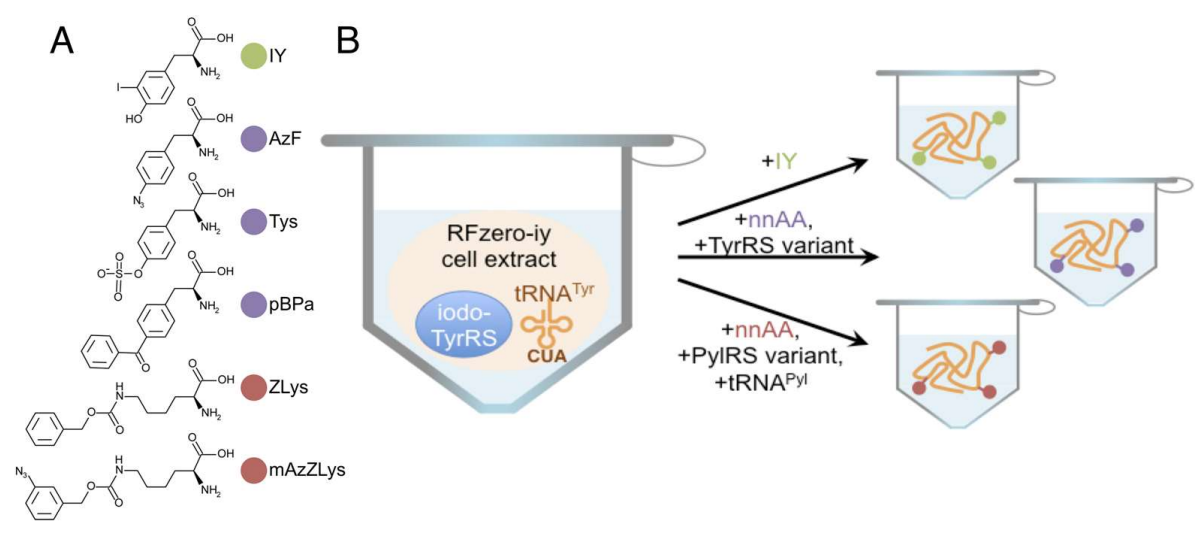

Figure 1. Incorporation of various non-natural amino acids by cell-free protein synthesis. (A) Structures of the non-natural amino acids used in this study. Colors indicate the types of non-natural amino acids shown in (B). (B) The concept of the RFzero-iy-based cell-free system for the incorporation of various non-natural amino acids, using a single type of cell extract. This strategy could be expanded to incorporate a variety of non-natural amino acids, by supplementing TyrRS variants, or $\mathrm{tRNA}^{\mathrm{Pyl}}$ and PylRS variant pairs. 


\section{Results}

\subsection{Comparison of RFzero Strains as S30 Extract Sources}

Since RFzero-iy exhibited the most vigorous growth among the variants of RFzero strains [23], we generated two types of RFzero-iy strains from an E. coli K-12 strain, BW25113, and an E. coli $\mathrm{B}$ strain, BL21(DE3). The growth rates of the generated strains were compared at $37{ }^{\circ} \mathrm{C}$ in $\mathrm{LB}$ medium and 2YT medium, which is richer in nutrients and commonly used for the preparation of S30 extracts. Both strains exhibited almost the same growth profiles in LB medium (Figure 2A), and the BW25113-based RFzero-iy reached a slightly higher cell density in 2YT medium (Figure 2B).

To confirm their utility as S30 extract strains, both strains were grown in $2 \mathrm{YT}$ at $37{ }^{\circ} \mathrm{C}$ for three hours and harvested before entering the late-log phase. As shown in Figure 2B, the cell densities at the harvest point were similar between the two strains, and comparable amounts of S30 extract were obtained from them. The small-scale dialysis-mode cell-free protein synthesis of the chloramphenicol acetyltransferase (CAT) protein was conducted with these S30 extracts, to confirm the protein productivity (Figure 2C). The BL21(DE3)-based RFzero-iy S30 extract produced a significantly larger amount of CAT, as compared to the BW25113-based RFzero-iy S30 extract. This result is consistent with the previous report showing that the S30 extract from a BL21 strain is more productive than the extract from a K-12 strain [26]. Thus, we decided to use the BL21(DE3)-based RFzero-iy strain in further experiments.
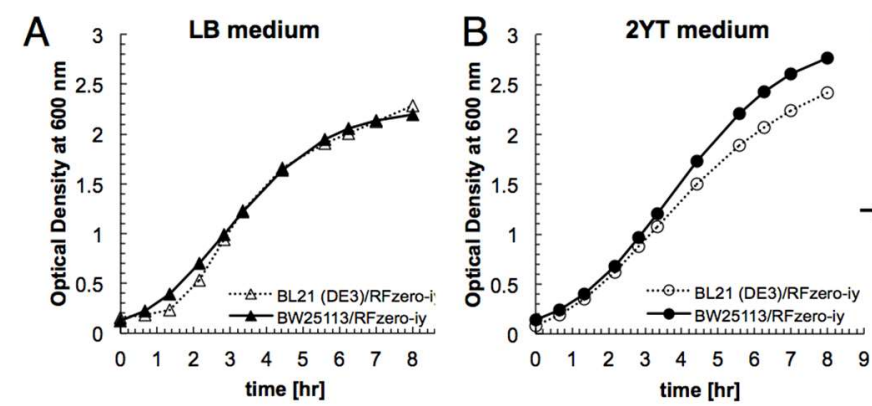

C

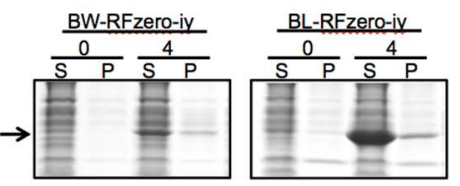

Figure 2. Comparison of RFzero strains derived from E. coli K- and B-strains as sources of S30 cell extracts. The growth profiles of the BW25113- and BL21(DE3)-based RFzero-iy strains in LB (A) and 2YT (B) at $37^{\circ} \mathrm{C}$, and the cell-free protein synthesis of Chloramphenicol acetyltransferase (CAT) with the S30 extracts from these strains (C). Aliquots of the reaction solution from the cell-free protein synthesis were taken at 0 and $4 \mathrm{~h}$, and analyzed by SDS-PAGE with Coomassie Brilliant Blue staining. "S" and "P" indicate the soluble and insoluble fractions, respectively. The arrow indicates the position of CAT.

\subsection{Optimization of S30 Extract Preparation from BL21(DE3)-based RFzero-iy}

For the growth of RFzero-iy, supplementation of IY is required in the growth media [22]. However, if a significant level of IY from the media contaminates the S30 extract, then the extract would translate the UAG codon to IY, and the ability of the RFzero-iy extract would be unintentionally limited to IY. To minimize this risk, we attempted to reduce the concentration of IY, which is generally supplemented at $0.1 \mathrm{mg} / \mathrm{mL}$. However, a reduction to one-tenth of this IY concentration hampered the bacterial growth and decreased the cell density by $80 \%$ at the late-log phase. Thus, we decided to continue supplementing IY at $0.1 \mathrm{mg} / \mathrm{mL}$, and searched for other approaches.

Temperature and aeration rate are two other common factors affecting bacterial growth. Since the cultivation of E. coli at $30^{\circ} \mathrm{C}$ reportedly enhances the productivity of the S30 extract [27], we decided to grow RFzero-iy at $30^{\circ} \mathrm{C}$ in the subsequent experiments.

We then examined the effect of the aeration during the cell culture, using baffled flasks and a jar fermenter with different airflow rates (Figure 3A). The culture in the baffled flask reached a higher cell density than that the standard flask. For the jar fermenter, an airflow rate of $3.5 \mathrm{~L} / \mathrm{min}$ considerably 
improved the cell growth, as compared to $0.5 \mathrm{~L} / \mathrm{min}$. Both results indicate that the growth of RFzero-iy is effectively enhanced with better aeration. Since the jar fermenter produced a comparable cell mass to that of the baffled flask, we decided to use the jar fermenter for the further preparation of large amounts of RFzero-iy S30 extracts.
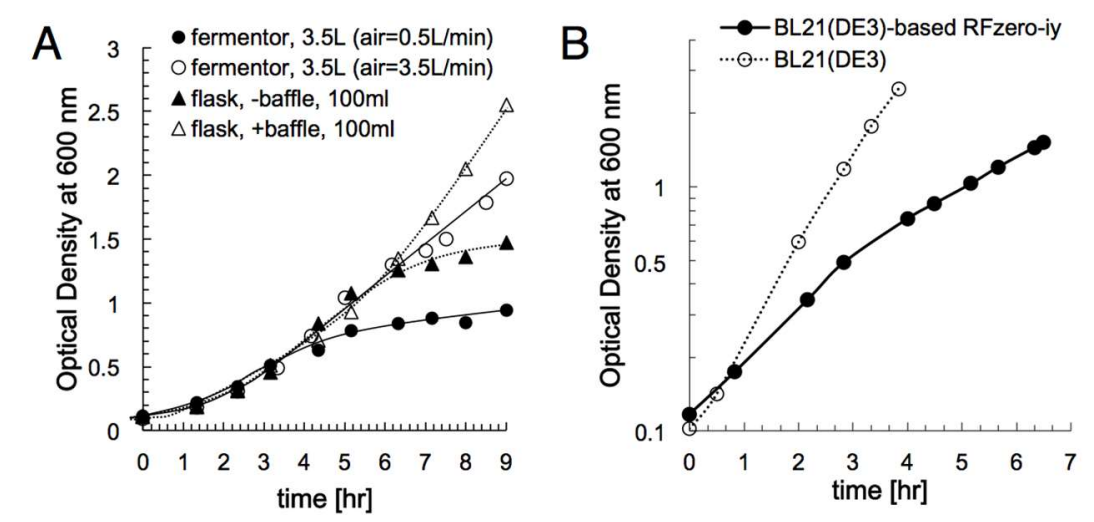

Figure 3. Growth profiles of RFzero-iy and BL21(DE3). (A) BL21(DE3)-based RFzero-iy was grown in a standard flask (filled triangles), a baffled flask (open triangles), and a jar fermenter with air supply rates of $0.5 \mathrm{~L} / \mathrm{min}$ (filled circles) and $3.5 \mathrm{~L} / \mathrm{min}$ (open circles). (B) BL21(DE3) (open circles) and BL21(DE3)-based RFzero-iy (filled circles), grown in jar fermenters at $30{ }^{\circ} \mathrm{C}$.

\subsection{Protein Productivity of S30 Extract from BL21(DE3)-Based RFzero-iy}

To confirm the protein productivity of cell-free systems, using S30 extracts from RFzero-iy and its parent strain BL21(DE3), the S30 extracts were prepared as follows. Both strains were cultivated in the jar fermenters with the $3.5 \mathrm{~L} / \mathrm{min}$ airflow rate at $30^{\circ} \mathrm{C}$. The growth rate of RFzero-iy was significantly slower than that of BL21(DE3) (Figure 3B). The RFzero-iy cells were harvested at $1.5 \mathrm{OD}_{600}$ after $7 \mathrm{~h}$, while the BL21(DE3) cells were harvested at $2.5 \mathrm{OD}_{600}$ after a $4 \mathrm{~h}$. The volume of the S30 extract obtained from a 1-1 cell culture was $3.0 \mathrm{ml}$ for RFzero-iy, corresponding to $57 \%$ of that of BL21(DE3).

The dialysis-mode cell-free protein synthesis of wild-type GFPS2 was conducted, using the produced S30 extracts in the presence and absence of IY (Figure 4). The protein productivity with the RFzero-iy-based S30 extract was about $60 \%$ of that of BL21(DE3). No significant differences were obtained with or without IY, using both S30 extracts. Thus, although the total productivity of the S30 extract was lower with RFzero-iy, the property of the S30 extracts corresponding to IY seems to be similar.

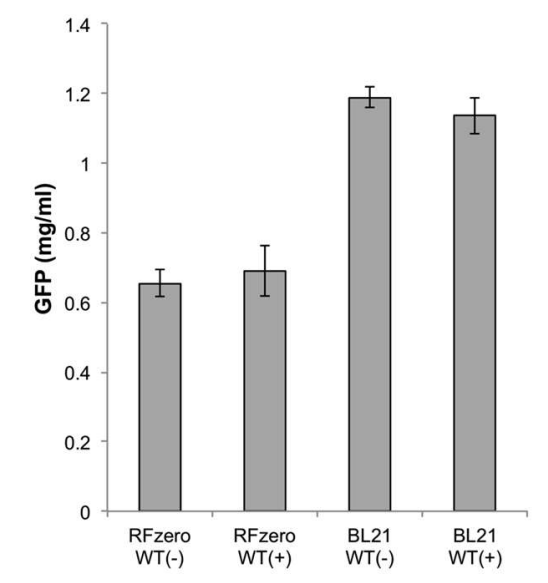

Figure 4. Protein productivity of RFzero-iy and BL21(DE3)-based S30 extracts. The cell-free protein synthesis of wild type GFPS2 was conducted with (+) or without (-) IY supplementation, using RFzero-iy-based S30 extracts (RFzero WT) and BL21(DE3)-based S30 extracts (BL21 WT). 


\subsection{Incorporation of IY in Response to UAG in RFzero-iy-Based Cell-Free System}

The dialysis-mode cell-free protein synthesis using the RFzero-iy-based S30 extract was conducted, to examine the incorporation efficiencies of IY at various UAG codon sites. This IY is a non-natural amino acid that has been incorporated into proteins, for purposes such as labeling and conferring heat resistance, and has actually been used for X-ray crystallographic analyses.

The tyrosine codons in pN11-GFPS2 at positions 21, 88, 192, 231, and 249 were individually replaced with UAG codons. With IY supplementation, the GFPS2 variants were efficiently synthesized, with productivities of more than $90 \%$ as compared to the amount of the wild-type GFPS2 (Figure 5A). These results indicate that the RFzero-iy-based S30 extract is highly effective for the site-specific incorporation of IY into various positions within the structure of the target protein.

Meanwhile without IY supplementation, hardly any full length GFPS2 variant proteins were synthesized and exhibited the fluorescence. These data also indicate that there was not significant contamination of IY in the RFzero-iy-based S30 extract from the growth media. Thus, the UAG codon of the template plasmid was kept unassigned in the RFzero-iy-based S30 extract, with neither RF-1 nor aminoacylated $t R N A$ recognizing the UAG codon. Although the extract contains the iodoTyrRS and UAG-reading tRNA ${ }^{\mathrm{Tyr}}$, the tRNA ${ }^{\mathrm{Tyr}}$ was uncharged without IY in the cell-free reaction mixture, and was thus non-functional for protein synthesis. This result suggests that the RFzero-iy-based S30 extract has the potential to incorporate other non-natural amino acids, by supplementing various orthogonal tRNA and aaRS pairs into the cell-free protein synthesis solution (Figure 1B).
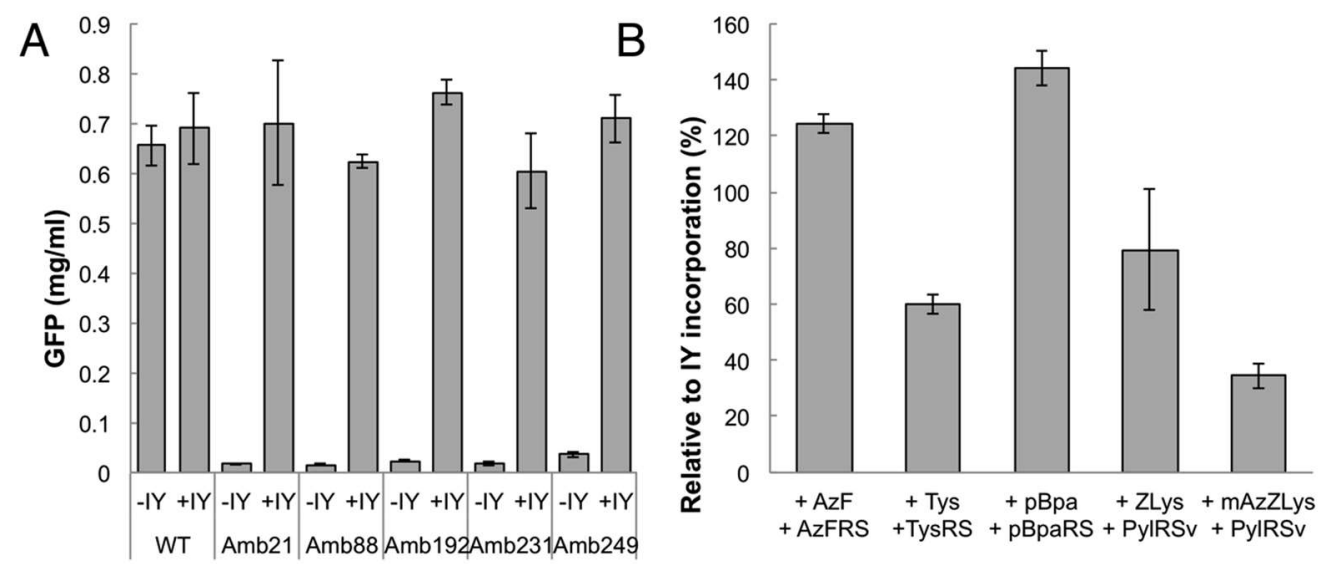

Figure 5. RFzero-iy-based cell-free system for non-natural amino acid incorporation. (A) The cell-free protein synthesis of wild-type N11-GFPS2 and UAG codon incorporated N11-GFPS2 mutants, with (+) or without (-) IY supplementation, were conducted with RFzero-iy-based S30 extracts. Wild-type GFPS2 is indicated as "WT", and GFPS2 variants with UAG codons are indicated with the position numbers indicated after the prefix "Amb". (B) The cell-free protein synthesis of N11-GFPS2(Y21amb) with supplementations of various non-natural amino acids and aaRS pairs, using RFzero-iy-based S30 extracts. PylRS(R61K-Y384F-Y306A) variant is indicated as PylRSv. Values are relative to the GFPS2 productivity of IY incorporation.

\subsection{Reassignment of UAG to other Non-Natural Amino Acids in RFzero-iy-Based Cell-Free System}

Many other archaeal TyrRS variants have been designed, such as TysRS for O-sulfo-L-tyrosine (Tys, also designated as SfY $[23,28])$, AzFRS for $p$-azido-L-phenylalanine (AzF), and $p$ BpaRS for p-benzoyl-L-phenylalanine ( $p \mathrm{Bpa}$ ) [6]. Interestingly, PylRS exhibits unusually broad specificities for the substrates [29], and its designed variants accept multiple substrate amino acids. One of the variants, PylRS(R61K-Y384F-Y306A), successfully esterifies multiple lysine derivatives [30], such as $N^{\varepsilon}$-benzyloxycarbonyl-L-lysine (ZLys) [31], and $N^{\varepsilon}$ - (m-azidobenzyloxycarbonyl)-L-lysine (mAzZLys) [32] (Figure 1A). 
In the absence of IY, the supplemented TyrRS variants charge their specific tyrosine derivatives to the UAG-reading tRNA ${ }^{\text {Tyr }}$ within the RFzero-iy-based S30 extract, or the supplemented PylRS variant charges lysine derivatives to the supplemented tRNA ${ }^{\mathrm{Pyl}}$, and the UAG codon is then reassigned for protein synthesis (Figure 1B). Using the combinations of AzFRS and AzF, TysRS, and Tys, $p$ BpaRS, and $p$ Bpa, PylRS(R61K-Y384F-Y306A) and ZLys, and PylRS(R61K-Y384F-Y306A) and mAzZLys, all of the aaRSs charged the non-natural amino acids, and the full length N11-GFPS2 variants were synthesized by the RFzero-iy-based cell-free system (Figure 5B). Among these non-natural amino acids, AzF and $p$ Bpa were incorporated as efficiently as IY. The incorporation efficiency decreased in the order of ZLys, Tys, and mAzZLys. The incorporation site Y21 is located in the linker sequence of pN11-GFPS2, outside of the GFP, and therefore the effects of the incorporated non-natural amino acids on the fluorescent intensity are presumed to be small. On the other hand, the aminoacylation activities of aaRSs vary with each non-natural amino acid, and the incorporation rates of non-natural amino acids may vary during translation. Thus, these differences in the incorporation rates of the non-natural amino acids shown in Figure 5B are presumed to arise from the differences in the aaRS activities with each non-natural amino acid, and the differences in the incorporation rates of non-natural amino acids.

This result demonstrated that the UAG codon, in the unassigned codon state, could easily be reassigned to any other desired non-natural amino acid by supplementing the cell-free reaction mixture, using a single type of cell extract, with a specific aaRS variant and UAG-reading tRNA pair. Furthermore, the high incorporation efficiency at the UAG codon is expected to allow the incorporation of non-natural amino acids at multiple positions within target proteins.

\section{Discussion}

In this study, we developed a method to prepare cell extracts from E. coli RFzero strains for the site-specific incorporation of non-natural amino acids using the extract-based cell-free protein synthesis. The open nature of the cell-free system is fundamentally suitable for the protein incorporation of non-natural amino acids, which are sometimes toxic or poor in cellular uptakes. The deletion of the RF-1 activity from E. coli strains is the key for the efficient incorporation of the non-natural amino acids using UAG stop codons. Thus, this strategy, combining the cell-free synthesis method with an RF-1-free E. coli strain, is advantageous for a wide range of applications involving non-natural amino acid incorporation.

The incorporation of IY into several positions of GFPS2, by RFzero-iy-based cell-free protein synthesis, presented an interesting advantage. As a general rule of the codon context effect in E. coli, UAG codons followed by $\mathrm{U}$ or $\mathrm{C}$ are translated less efficiently than UAGs followed by A or G [33]. However, even though the tested UAG codon positions (21, 88, 192, 231, and 249) have neighboring codons with the first letters of $U, G, A, C$, and C, respectively, the effects of this codon context rule were not detected in the RFzero-based cell-free system (Figure 5A), and IYs were efficiently incorporated into all of the positions. Considering that the codon context effect is ascribed to the competition between the UAG-translating tRNA and RF-1 [34], it is quite reasonable that our present cell-free systems from the RF-1-free E. coli strains are not restricted to the context rule. Thus, the RFzero-iy-based cell-free system has the advantage that the positions for UAG codon insertion can be selected without consideration of the codon context effect, for highly efficient protein production.

Our RFzero-iy-based cell-free strategy is flexible and expandable. Once a cell extract is prepared, various non-natural amino acids could be incorporated, simply by supplementing the orthogonal aaRS and tRNA pairs, without any genetic engineering. There is no need to consider the effects on the growth of $E$. coli, which often matters during the in vivo incorporation of non-natural amino acids. We successfully incorporated acetyllysine at four positions in histone H4 [23], due to the efficient incorporation rate of the RFzero-iy-based cell-free system. Recently, we actually used the present RFzero-iy-based cell-free system for the structural analysis of a tetra-acetylated nucleosome core particle [35]. Therefore, we believe that our RFzero-iy-based cell-free strategy is useful to synthesize proteins with multiple, site-specifically incorporated non-natural amino acids (Figure 1). 
In previous studies of the site-specific incorporations of non-natural amino acids, several RF-1 deleted E. coli strains, with numerous replacements of UAG codons to the other stop codons, were shown to successfully improve the incorporation efficiencies. Likewise, several cell-free protein synthesis methods using the cell extracts from these strains exhibited high incorporation efficiencies [17-20]. Meanwhile, E. coli strains have been generated specifically for various reasons, and the demands to modify these $E$. coli genomes for the incorporation of non-natural amino acids will arise. Therefore, our method for generating the RFzero-iy strain, simply by transforming a BAC plasmid and deleting the prfA gene from the genome, which is more rapid and convenient than the other reported methods, represents a promising way to generate new RF-1-deleted E. coli strains from pre-existing strains with genomes modified for specific purposes. Using a single type of cell extract, we could incorporate several non-natural amino acids, some of which were incorporated with low efficiencies upon in vivo expression. Cell-free protein synthesis has the potential to incorporate non-natural amino acids that are difficult to incorporate by in vivo expression, due to their toxicities and low cellular uptakes. Taken together, the advantages of protein synthesis with the present RFzero-iy-based cell-free strategy will expand the potentials of diverse E. coli strains for non-natural amino acid incorporation, and it will be a promising technique for advanced protein engineering.

\section{Materials and Methods}

\subsection{Strains and Plasmids}

Escherichia coli BW25113 was provided by the National BioResource Project (Japan), and BL21(DE3) was purchased from Novagen (USA). The BW25113-based and BL21(DE3)-based RFzero-iy strains were generated as described previously [8]. For the expression of chloramphenicol acetyltransferase (CAT), pk7-CAT [36] was used. For the expression of a superfolder-type GFP mutant, pN11-GFPS2, a plasmid encoding GFPS2 (GenBank: LC185343.1), which contains a poly-histidine affinity tag (N11, MKDHLIHNHHKHEHAHAEH), a protease site, and a GFPS1 [27] variant gene, in the pCR2.1 vector (Thermo Fisher Scientific, Waltham, MA, USA), was used. For the incorporation of non-natural amino acids, the tyrosine codons at positions 21, 88, 192, 231, and 249 in pN11-GFPS2 were individually replaced with a UAG codon, using a QuikChange Site-Directed Mutagenesis kit (Agilent Technologies, Santa Clara, CA, USA). In addition to the Y88amb mutation, the plasmid pN11-GFPS2(Y88amb) had the Y249C mutation, due to a PCR error.

\subsection{Non-Natural Amino Acids}

The non-natural amino acids were purchased from the following companies: 3-Iodo-L-tyrosine (IY) from Sigma-Aldrich (St. Louis, MO, USA) and Tokyo Chemical Industry (Tokyo, Japan), 4-Azido-L-phenylalanine (AzF), $p$-benzoyl-L-phenylalanine ( $p$ Bpa), and $N^{\varepsilon}$-benzyloxycarbonyl-L-lysine (ZLys) from Bachem (Switzerland), O-Sulfo-L-tyrosine (Tys) from Watanabe Chemical Industries (Hiroshima, Japan), and $N^{\varepsilon}-$ (m-azidobenzyloxycarbonyl)-L-lysine (mAzZLys) from Sundia (Shanghai, China).

\subsection{Cell Culture}

To examine the growth profiles, the cells were grown at $37^{\circ} \mathrm{C}$ in $5 \mathrm{~mL}$ of LB medium or $2 \mathrm{YT}$ medium (16 g tryptone, $10 \mathrm{~g}$ yeast extract, $5 \mathrm{~g} \mathrm{NaCl}$ per liter). To the media, chloramphenicol $(\mathrm{Cm})$ was added at $10 \mathrm{mg} / \mathrm{L}$, and IY was added at $0.1 \mathrm{mg} / \mathrm{mL}$. All of the culture tubes were shaken at $200 \mathrm{rpm}$.

To prepare the S30 cell extracts, the cells were preliminarily grown at $37^{\circ} \mathrm{C}$ overnight in $200 \mathrm{~mL}$ of 2YT medium supplemented with $10 \mathrm{mg} / \mathrm{L} \mathrm{Cm}$ and $0.1 \mathrm{mg} / \mathrm{mL}$ IY, in 1-liter or 2-liter baffled flasks shaken at $110-120 \mathrm{rpm}$.

For preparing S30 cell extracts with baffled flasks, the overnight culture was added to $2 \mathrm{~L}$ of $2 \mathrm{YT}$ medium to an initial cell density higher than $0.1 \mathrm{OD}_{600}$, with $10 \mathrm{mg} / \mathrm{L} \mathrm{Cm}$ and $0.1 \mathrm{mg} / \mathrm{mL}$ IY in a 
5-liter baffled flask, and incubated at $30{ }^{\circ} \mathrm{C}$ with continuous shaking at $110-120 \mathrm{rpm}$. The cells were harvested at the late-log phase.

For preparing S30 cell extracts with a jar fermenter, the overnight culture was added to $16 \mathrm{~L}$ of 2YT medium with $10 \mathrm{mg} / \mathrm{L} \mathrm{Cm}$ and $0.1 \mathrm{mg} / \mathrm{mL}$ IY in a 30 -liter fermenter $\left(37^{\circ} \mathrm{C}, 220 \mathrm{rpm}\right)$, to an initial cell density higher than $0.1 \mathrm{OD}_{600}$. The cells were harvested at the late-log phase.

\subsection{S30 Preparation}

The S30 cell extracts were prepared as described previously [26,27]. The cells were harvested at the late-log phase and then washed three times with S30 buffer A (10 mM Tris-acetate buffer ( $\mathrm{pH}$ 8.2) containing $14 \mathrm{mM} \mathrm{Mg}(\mathrm{OAc})_{2}, 60 \mathrm{mM}$ potassium acetate, and $2 \mathrm{mM}$ DTT). The washed cells were suspended in S30 buffer B (S30 buffer A with $1 \mathrm{mM} \mathrm{DTT)} \mathrm{and} \mathrm{crushed} \mathrm{with} \mathrm{glass} \mathrm{beads}$ ( $\varnothing=0.17-0.18 \mathrm{~mm}$, B. Braun, Hessen, Germany), using a multi-bead shocker (Yasui Kikai, Osaka, Japan) three times at $2700 \mathrm{rpm}$ for $30 \mathrm{~s}$. For treating $1 \mathrm{~g}$ of cells, $1.25 \mathrm{~mL}$ of S30 buffer B and $3.15 \mathrm{~g}$ of glass beads were used. The cell debris and glass beads were removed by two rounds of centrifugation at $30,000 \times \mathrm{g}$ for $30 \mathrm{~min}$ at $4{ }^{\circ} \mathrm{C}$. The obtained supernatant was mixed with a 0.3 -fold volume of pre-incubation buffer (293 mM Tris-acetate buffer ( $\mathrm{pH}$ 8.2) containing $9 \mathrm{mM} \mathrm{Mg}(\mathrm{OAc})_{2}, 13.2 \mathrm{mM}$ ATP, $84 \mathrm{mM}$ phosphoenolpyruvate, $4.4 \mathrm{mM} \mathrm{DTT}, 20$ amino acids (40 M each), and $6.7 \mathrm{U} / \mathrm{mL}$ pyruvate kinase), and incubated for $70-80 \mathrm{~min}$ at $37^{\circ} \mathrm{C}$. The crude extract was dialyzed three or four times against a 50-fold volume of S30 buffer B, for $45-60 \mathrm{~min}$ at $4{ }^{\circ} \mathrm{C}$. The cell extract was then centrifuged at $4000 \times g$ for $10 \mathrm{~min}$ at $4{ }^{\circ} \mathrm{C}$, to obtain the supernatant as the S30 cell extract. Aliquots of the extract were immediately frozen in liquid nitrogen, and stored in liquid nitrogen or below $-80^{\circ} \mathrm{C}$.

For preparing S30 cell extracts with a jar fermenter, the cells were harvested at the late-log phase and washed three times in S30 buffer B. The washed cells were suspended in the corresponding volume of S30 buffer B per weight ( $1 \mathrm{~mL}$ per $1 \mathrm{~g}$ cells) and crushed with a high-pressure homogenizer (Stansted, UK), which was operated at 170-200 MPa. The cell debris was removed by two rounds of centrifugation at $30,000 \times \mathrm{g}$ for $30 \mathrm{~min}$ at $4{ }^{\circ} \mathrm{C}$. The following procedures were conducted according to the baffled flask method.

\subsection{Cell-Free Protein Synthesis}

The small-scale dialysis-mode cell-free protein synthesis with a $30 \mu \mathrm{l}$ reaction mixture was performed as described previously [37]. Chloramphenicol acetyltransferase (CAT) synthesis was performed at $30^{\circ} \mathrm{C}$. Synthesis of a superfolder-type GFP mutant, GFPS2 (GenBank: LC185343.1) was performed at $25^{\circ} \mathrm{C}$, without polyethlene glycol. All of the reactions were shaken at $240 \mathrm{rpm}$ for $4 \mathrm{~h}$. IY was supplemented at $1.0 \mathrm{mM}$ in both the reaction and external solutions. Other tyrosine derivatives were supplemented at $1.0 \mathrm{mM}$ to both solutions, with their specific TyrRS variants added to the reaction solution at $0.3 \mu \mathrm{g} / \mu \mathrm{l}$. Lysine derivatives were supplemented at $1.0 \mathrm{mM}$ to both solutions, with a tRNA $^{\text {Pyl }}$ and a pyrrolysyl-tRNA synthetase variant, PylRS(R61K-Y384F-Y306A) [30], added to the reaction solution at $10 \mu \mathrm{M}$ each.

\subsection{Detection of Protein Synthesis}

For the SDS-PAGE analysis, a $5-\mu \mathrm{L}$ aliquot of the reaction solution was centrifuged, and the insoluble fractions were suspended in SDS sample buffer. The supernatants were mixed with $40 \mu \mathrm{L}$ ice-cold $75 \%$ acetone, incubated at $-20{ }^{\circ} \mathrm{C}$ for $30 \mathrm{~min}$, and centrifuged to remove the polyethylene glycol. The precipitated proteins were then suspended in SDS sample buffer, as the soluble fraction. SDS-PAGE was performed on a $2-20 \%$ gradient gel, which was then stained with Coomassie Brilliant Blue. The GFPS2 fluorescence was measured using a fluorescence plate reader, ARVO SX (PerkinElmer, Waltham, MA, USA), with excitation at $485 \mathrm{~nm}$ and emission at $535 \mathrm{~nm}$. The purified wild-type GFPS2 was used as the standard to calculate the productivity. 
Author Contributions: Conceptualization, S.Y.; Funding acquisition, S.Y.; Methodology, J.A., K.K., E.S. and T.M.; Validation, C.T., M.S., T.T., K.S. and S.Y.; Writing-original draft, J.A., E.S., C.T., K.S. and S.Y.; Writing-review \& editing, K.K., E.S., M.S., T.T. and T.M.

Funding: This study was supported by the Targeted Proteins Research Program from the Ministry of Education, Culture, Sports, Science and Technology (MEXT) of Japan, by the Platform Project for Supporting in Drug Discovery and Life Science Research (Platform for Drug Discovery, Informatics, and Structural Life Science) from MEXT and Japan Agency for Medical Research and Development (AMED), and by the Platform Project for Supporting Drug Discovery and Life Science Research (Basis for Supporting Innovative Drug Discovery and Life Science Research (BINDS)) from AMED under Grant Number JP17am0101081.

Acknowledgments: The authors thank N. Ohsawa, M. Inoue, M. Matsuda, and K. Ishii for creating GFP plasmids.

Conflicts of Interest: S.Y., K.S., and T.M. received funding from company names not available during the conduct of the study. The funders had no role in the design of the study.; S.Y., K.S., and T.M. have patents issued related to this study.

\section{Abbreviations}

$\begin{array}{ll}\text { RF-1 } & \text { Release factor 1 } \\ \text { IY } & \text { 3-iodo-L-tyrosine } \\ \text { aaRS } & \text { Aminoacyl-tRNA synthetase } \\ \text { CAT } & \text { Chloramphenicol acetyltransferase } \\ \text { Tys } & \text { O-Sulfo-L-tyrosine } \\ \text { AzF } & \text { 4-Azido-L-phenylalanine } \\ p \text { Bpa } & p \text {-benzoyl-L-phenylalanine } \\ m \text { AzZLys } & N^{\varepsilon} \text { - (m-azidobenzyloxycarbonyl)-L-lysine } \\ \text { ZLys } & N^{\varepsilon} \text {-benzyloxycarbonyl-L-lysine } \\ \text { Cm } & \text { Chloramphenicol }\end{array}$

\section{References}

1. Terada, T.; Kusano, S.; Matsuda, T.; Shirouzu, M.; Yokoyama, S. Cell-Free Protein Production for Structural Biology. Adv. Methods Struct. Biol. 2016, 83-102. [CrossRef]

2. Shinoda, T.; Shinya, N.; Ito, K.; Ishizuka-Katsura, Y.; Ohsawa, N.; Terada, T.; Hirata, K.; Kawano, Y.; Yamamoto, M.; Tomita, T.; et al. Cell-free methods to produce structurally intact mammalian membrane proteins. Sci. Rep. 2016, 6, 30442. [CrossRef] [PubMed]

3. Yokoyama, J.; Matsuda, T.; Koshiba, S.; Tochio, N.; Kigawa, T. A practical method for cell-free protein synthesis to avoid stable isotope scrambling and dilution. Anal. Biochem. 2011, 411, 223-229. [CrossRef] [PubMed]

4. Jackson, M.; Pratt, J.M.; Holland, I.B. Enhanced polypeptide synthesis programmed by linear DNA fragments in cell-free extracts lacking exonuclease V. FEBS Lett. 1983, 163, 221-224. [CrossRef]

5. Seki, E.; Matsuda, N.; Kigawa, T. Multiple inhibitory factor removal from an Escherichia coli cell extract improves cell-free protein synthesis. J. Biosci. Bioeng. 2009, 108, 30-35. [CrossRef] [PubMed]

6. Liu, C.C.; Schultz, P.G. Adding new chemistries to the genetic code. Annu. Rev. Biochem. 2010, 79, 413-444. [CrossRef] [PubMed]

7. Yanagisawa, T.; Umehara, T.; Sakamoto, K.; Yokoyama, S. Expanded Genetic Code Technologies for Incorporating Modified Lysine at Multiple Sites. ChemBioChem 2014, 15, 2181-2187. [CrossRef]

8. Noren, C.; Anthony-Cahill, S.; Griffith, M.; Schultz, P. A general method for site-specific incorporation of unnatural amino acids into proteins. Science 1989, 244, 182-188. [CrossRef]

9. Hong, S.H.; Kwon, Y.C.; Jewett, M.C. Non-standard amino acid incorporation into proteins using Escherichia coli cell-free protein synthesis. Front. Chem. 2014, 2, 34. [CrossRef]

10. Sando, S.; Ogawa, A.; Nishi, T.; Hayami, M.; Aoyama, Y. In vitro selection of RNA aptamer against Escherichia coli release factor 1. Bioorg. Med. Chem. Lett. 2007, 17, 1216-1220. [CrossRef]

11. Shimizu, Y.; Inoue, A.; Tomari, Y.; Suzuki, T.; Yokogawa, T.; Nishikawa, K.; Ueda, T. Cell-free translation reconstituted with purified components. Nat. Biotechnol. 2001, 19, 751-755. [CrossRef] [PubMed]

12. Loscha, K.V.; Herlt, A.J.; Qi, R.; Huber, T.; Ozawa, K.; Otting, G. Multiple-site labeling of proteins with unnatural amino acids. Angew. Chem. Int. Ed. 2012, 51, 2243-2246. [CrossRef] [PubMed] 
13. Johnson, D.B.F.; Xu, J.; Shen, Z.; Takimoto, J.K.; Schultz, M.D.; Schmitz, R.J.; Xiang, Z.; Ecker, J.R.; Briggs, S.P.; Wang, L. RF1 knockout allows ribosomal incorporation of unnatural amino acids at multiple sites. Nat. Chem. Biol. 2011, 7, 779-786. [CrossRef] [PubMed]

14. Heinemann, I.U.; Rovner, A.J.; Aerni, H.R.; Rogulina, S.; Cheng, L.; Olds, W.; Fischer, J.T.; Söll, D.; Isaacs, F.J.; Rinehart, J. Enhanced phosphoserine insertion during Escherichia coli protein synthesis via partial UAG codon reassignment and release factor 1 deletion. FEBS Lett. 2012, 586, 3716-3722. [CrossRef] [PubMed]

15. Lajoie, M.J.; Rovner, A.J.; Goodman, D.B.; Aerni, H.-R.; Haimovich, A.D.; Kuznetsov, G.; Mercer, J.A.; Wang, H.H.; Carr, P.A.; Mosberg, J.A.; et al. Genomically recoded organisms expand biological functions. Science 2013, 342, 357-360. [CrossRef] [PubMed]

16. Mukai, T.; Hoshi, H.; Ohtake, K.; Takahashi, M.; Yamaguchi, A.; Hayashi, A.; Yokoyama, S.; Sakamoto, K. Highly reproductive Escherichia coli cells with no specific assignment to the UAG codon. Sci. Rep. 2015, 5, 9699. [CrossRef] [PubMed]

17. Hong, S.H.; Ntai, I.; Haimovich, A.D.; Kelleher, N.L.; Isaacs, F.J.; Jewett, M.C. Cell-free Protein Synthesis from a Release Factor 1 Deficient Escherichia coli Activates Efficient and Multiple Site-specific Nonstandard Amino Acid Incorporation. ACS Synth. Biol. 2014, 3, 398-409. [CrossRef]

18. Chemla, Y.; Ozer, E.; Schlesinger, O.; Noireaux, V.; Alfonta, L. Genetically expanded cell-free protein synthesis using endogenous pyrrolysyl orthogonal translation system. Biotechnol. Bioeng. 2015, 112, 1663-1672. [CrossRef]

19. Martin, R.W.; Des Soye, B.J.; Kwon, Y.-C.; Kay, J.; Davis, R.G.; Thomas, P.M.; Majewska, N.I.; Chen, C.X.; Marcum, R.D.; Weiss, M.G.; et al. Cell-free protein synthesis from genomically recoded bacteria enables multisite incorporation of noncanonical amino acids. Nat. Commun. 2018, 9, 1203. [CrossRef]

20. Seki, E.; Yanagisawa, T.; Yokoyama, S. Cell-Free Protein Synthesis for Multiple Site-Specific Incorporation of Noncanonical Amino Acids Using Cell Extracts from RF-1 Deletion E. coli Strains. Methods Mol. Biol. 2018, 1728, 49-65. [CrossRef]

21. Fan, C.; Ip, K.; Söll, D. Expanding the genetic code of Escherichia coli with phosphotyrosine. FEBS Lett. 2016, 590, 3040-3047. [CrossRef] [PubMed]

22. Mukai, T.; Hayashi, A.; Iraha, F.; Sato, A.; Ohtake, K.; Yokoyama, S.; Sakamoto, K. Codon reassignment in the Escherichia coli genetic code. Nucleic Acids Res. 2010, 38, 8188-8195. [CrossRef] [PubMed]

23. Mukai, T.; Yanagisawa, T.; Ohtake, K.; Wakamori, M.; Adachi, J.; Hino, N.; Sato, A.; Kobayashi, T.; Hayashi, A.; Shirouzu, M.; et al. Genetic-code evolution for protein synthesis with non-natural amino acids. Biochem. Biophys. Res. Commun. 2011, 411, 757-761. [CrossRef] [PubMed]

24. Kato, A.; Kuratani, M.; Yanagisawa, T.; Ohtake, K.; Hayashi, A.; Amano, Y.; Kimura, K.; Yokoyama, S.; Sakamoto, K.; Shiraishi, Y. Extensive Survey of Antibody Invariant Positions for Efficient Chemical Conjugation Using Expanded Genetic Codes. Bioconjug. Chem. 2017, 28, 2099-2108. [CrossRef] [PubMed]

25. Sakamoto, K.; Murayama, K.; Oki, K.; Iraha, F.; Kato-Murayama, M.; Takahashi, M.; Ohtake, K.; Kobayashi, T.; Kuramitsu, S.; Shirouzu, M.; et al. Genetic encoding of 3-iodo-L-tyrosine in Escherichia coli for single-wavelength anomalous dispersion phasing in protein crystallography. Structure 2009, 17, 335-344. [CrossRef] [PubMed]

26. Kigawa, T.; Yabuki, T.; Matsuda, N.; Matsuda, T.; Nakajima, R.; Tanaka, A.; Yokoyama, S. Preparation of Escherichia coli cell extract for highly productive cell-free protein expression. J. Struct. Funct. Genom. 2004, 5, 63-68. [CrossRef] [PubMed]

27. Seki, E.; Matsuda, N.; Yokoyama, S.; Kigawa, T. Cell-free protein synthesis system from Escherichia coli cells cultured at decreased temperatures improves productivity by decreasing DNA template degradation. Anal. Biochem. 2008, 377, 156-161. [CrossRef]

28. Guo, J.; Melançon, C.E.; Lee, H.S.; Groff, D.; Schultz, P.G. Evolution of amber suppressor tRNAs for efficient bacterial production of proteins containing nonnatural amino acids. Angew. Chem. Int. Ed. 2009, 48, 9148-9151. [CrossRef]

29. Wan, W.; Tharp, J.M.; Liu, W.R. Pyrrolysyl-tRNA synthetase: An ordinary enzyme but an outstanding genetic code expansion tool. Biochim. Biophys. Acta 2014, 1844, 1059-1070. [CrossRef]

30. Yanagisawa, T.; Ishii, R.; Fukunaga, R.; Kobayashi, T.; Sakamoto, K.; Yokoyama, S. Multistep engineering of pyrrolysyl-tRNA synthetase to genetically encode $N$ (epsilon)-(o-azidobenzyloxycarbonyl) lysine for site-specific protein modification. Chem. Biol. 2008, 15, 1187-1197. [CrossRef] 
31. Mukai, T.; Kobayashi, T.; Hino, N.; Yanagisawa, T.; Sakamoto, K.; Yokoyama, S. Adding L-lysine derivatives to the genetic code of mammalian cells with engineered pyrrolysyl-tRNA synthetases. Biochem. Biophys. Res. Commun. 2008, 371, 818-822. [CrossRef] [PubMed]

32. Yamaguchi, A.; Matsuda, T.; Ohtake, K.; Yanagisawa, T.; Yokoyama, S.; Fujiwara, Y.; Watanabe, T.; Hohsaka, T.; Sakamoto, K. Incorporation of a Doubly Functionalized Synthetic Amino Acid into Proteins for Creating Chemical and Light-Induced Conjugates. Bioconjug. Chem. 2016, 27, 198-206. [CrossRef] [PubMed]

33. Bossi, L. Context effects: Translation of UAG codon by suppressor tRNA is affected by the sequence following UAG in the message. J. Mol. Biol. 1983, 164, 73-87. [CrossRef]

34. Xu, H.; Wang, Y.; Lu, J.; Zhang, B.; Zhang, Z.; Si, L.; Wu, L.; Yao, T.; Zhang, C.; Xiao, S.; et al. Re-exploration of the Codon Context Effect on Amber Codon-Guided Incorporation of Noncanonical Amino Acids in Escherichia coli by the Blue-White Screening Assay. ChemBioChem 2016, 17, 1250-1256. [CrossRef] [PubMed]

35. Wakamori, M.; Fujii, Y.; Suka, N.; Shirouzu, M.; Sakamoto, K.; Umehara, T.; Yokoyama, S. Intra- and inter-nucleosomal interactions of the histone $\mathrm{H} 4$ tail revealed with a human nucleosome core particle with genetically-incorporated H4 tetra-acetylation. Sci. Rep. 2015, 5, 17204. [CrossRef] [PubMed]

36. Kim, D.-M.; Choi, C.Y. A semicontinuous prokaryotic coupled transcription/translation system using a dialysis membrane. Biotechnol. Prog. 1996, 12, 645-649. [CrossRef] [PubMed]

37. Matsuda, T.; Kigawa, T.; Koshiba, S.; Inoue, M.; Aoki, M.; Yamasaki, K.; Seki, M.; Shinozaki, K.; Yokoyama, S. Cell-free synthesis of zinc-binding proteins. J. Struct. Funct. Genom. 2006, 7, 93-100. [CrossRef]

(C) 2019 by the authors. Licensee MDPI, Basel, Switzerland. This article is an open access article distributed under the terms and conditions of the Creative Commons Attribution (CC BY) license (http://creativecommons.org/licenses/by/4.0/). 